Check for updates

Cite this: RSC Adv., 2019, 9, 10058

Received 20th November 2018 Accepted 22nd March 2019

DOI: $10.1039 / c 8 r a 09557 d$

rsc.li/rsc-advances

\section{Revealing hydrogen atoms in a highly-absorbing material: an X-ray diffraction study and Torque method calculations for lead-uranyl-oxide mineral curite $\uparrow$}

\author{
Seyedayat Ghazisaeed, ${ }^{a}$ Boris Kiefer (D) a and Jakub Plášil (DD *b
}

The crystal structure of lead uranyl-oxide hydroxy-hydrate mineral curite, ideally $\mathrm{Pb}_{3}\left(\mathrm{H}_{2} \mathrm{O}\right)_{2}\left[\left(\mathrm{UO}_{2}\right)_{4} \mathrm{O}_{4}(\mathrm{OH})_{3}\right]_{2}$, was studied by means of single-crystal X-ray diffraction and theoretical calculations in order to localize positions of hydrogen atoms in the structure. This study has demonstrated that hydrogen atoms can be localized successfully also in materials for which the conventional approach of structure analysis failed, here due to very high absorption of X-rays by the mineral matrix. The theoretical calculations, based on the Torque method, provide a robust, fast realspace method for determining $\mathrm{H}_{2} \mathrm{O}$ orientations from their rotational equilibrium condition. In line with previous results we found that curite is orthorhombic, with space group Pnma, unit-cell parameters $a=$ $12.5510(10), b=8.3760(4), c=13.0107(9) \AA, V=1367.78(16) \AA^{3}$, and two formula units per unit cell. The structure $\left(R_{1}=3.58 \%\right.$ for 1374 reflections with $\left.I>3 \sigma l\right)$ contains uranyl-hydroxo-oxide sheets of the unique topology among uranyl oxide minerals and compounds and an interlayer space with $\mathrm{Pb}^{2+}$ cations and a single $\mathrm{H}_{2} \mathrm{O}$ molecule, which is coordinated to the $\mathrm{Pb}$-site. Current results show that curite is slightly non-stoichiometric in $\mathrm{Pb}$ content $(\sim 3.02 \mathrm{~Pb}$ per unit cell, $Z=2)$; the charge-balance mechanism is via $(\mathrm{OH}) \leftrightarrow \mathrm{O}_{2}$ substitution within the sheets of uranyl polyhedra. Disproving earlier predictions, the current study shows that curite contains only one $\mathrm{H}_{2} \mathrm{O}$ group, with [4]-coordinated oxygen. The hydrogen bonding network maintains the bonding between the sheets in addition to $\mathrm{Pb}-\mathrm{O}$ bonds; among them, a $\mathrm{H}$-bond is crucial between the $\mathrm{OH}$ group on an apical Ouranyl atom of an adjacent sheet that stabilizes the entire structure. The results show that the combination of experimental X-ray data and the Torque method can successfully reveal hydrogen bonding especially for complex crystal structures and materials where $\mathrm{X}$-rays fail to provide unambiguous hydrogen positions.

\section{Introduction}

Uranyl-oxide hydroxy-hydrate minerals (further called as UOH) are important products of oxidizing weathering of primary uranium minerals, namely uraninite $\left(\mathrm{UO}_{2+x}\right)$, and one of the major constituents of the oxidized parts of uranium deposits. ${ }^{1,2}$ These minerals form in the initial stages of uraninite alteration, commonly replacing it in situ.$^{3-5}$ Weathering of uraninite is of great interest because of its analogy to the alteration of $\mathrm{UO}_{2+x}$ in spent nuclear fuel, SNF. ${ }^{6}$ Therefore, the precise knowledge of physical-chemical properties of $\mathrm{UOH}$ and the uranyl mineral is

${ }^{a}$ Department of Physics, New Mexico State University, Las Cruces, NM 88003, USA ${ }^{b}$ Institute of Physcis, Academy of Sciences of the Czech Republic, v.v.i, Na Slovance 2, Prague 18221, Czech Republic.E-mail: plasil@fzu.cz

$\uparrow$ Electronic supplementary information (ESI) available: Atom positions, equivalent and anisotropic displacement parameters, and interatomic distances; crystallographic information file. CCDC 1880074. For ESI and crystallographic data in CIF or other electronic format see DOI: 10.1039/c8ra09557d crucial for the assessment of their role and behavior during long-term storage of SNF and the non-desirable migration of uranium and transuranic elements in the environment. ${ }^{7,8}$

To date, about twenty-eight $\mathrm{UOH}$ minerals are known to occur in nature and a dozen more compounds have been synthesized. ${ }^{5,9,10}$ In general, their crystal structures are based upon sheets of $\mathrm{U}(\mathrm{vI})$ coordination polyhedra, where the ligands comprise $\mathrm{O}$ atoms or $(\mathrm{OH})^{-}$groups, less frequently also $\mathrm{H}_{2} \mathrm{O}$ molecules. Among sheets of uranyl-polyhedra we can discern various uranyl-anion topologies, following previous work. ${ }^{11,12}$ Between the sheets, mono-, di-, or trivalent cations and $\mathrm{H}_{2} \mathrm{O}$ molecules are located., ${ }^{5,13}$ There are just four minerals known to contain $\mathrm{H}_{2} \mathrm{O}$ molecules in the interlayer only; their structures are stabilized by an extensive network of H-bonds (schoepite, metaschoepite, paulscherrerite and heisenbergite). ${ }^{14-18}$

In general, the thermodynamic stability of the structures of layered hydrated oxysalts is driven by the weak bonding interactions taking place between the rigid parts of the structure (called structure units) and interlayer regions usually 
containing only hydrated cations or $\mathrm{H}_{2} \mathrm{O}$ molecules. ${ }^{19-22}$ Resolving hydrogen locations in crystal structures of hydrated uranium oxysalts is thus crucial for advancing our understanding of the thermodynamic stability and thus potential release of uranium into the environment. This is the case of complex uranyl-oxide phases and minerals, which are known for their extensive H-bonding, which drives their stabilities and affecting their occurrence in nature. ${ }^{23}$ Despite of the importance, a complete crystallographic data set (including positions of $\mathrm{H}$ atoms) are available only for few of these minerals. The major challenges in direct determination of $\mathrm{H}$-atoms positions are the high absorption of X-ray and small or poorly developed crystals available for the structure analysis. Therefore, the combination of methods, usually comprising XRD structure determination and with the parameter from Density Functional Theory (DFT) optimization of crystal structure, has become to be used more widely. ${ }^{24-26}$

The current study demonstrates the possibility of elucidation $\mathrm{H}$ atoms in the structure of highly-absorbing material for $\mathrm{X}$ rays, where the localization of hydrogens remains poorly constraint. Here, we demonstrate the successful hydrogen atom localization by combining X-ray diffraction and a recently developed Torque method. ${ }^{27}$

\section{Methods}

\section{Sample}

The phase of interest in our study is the mineral curite, originally described in 1921 by Alfred Schoep from Shinkolobwe mine, Shaba province, Democratic Republic of Congo, Africa, as $2 \mathrm{PbO} \cdot 5 \mathrm{UO}_{3} \cdot 4 \mathrm{H}_{2} \mathrm{O} .{ }^{28}$ Curite is an important product of uraninite weathering, occurring at the very mature stages or uraninite alteration. It is characteristic for the high molar proportion of $\left(\mathrm{Me}^{2+}+\mathrm{U}\right)$ and a low $\mathrm{H}_{2} \mathrm{O}$ content. The most recent crystalstructure determination on a series of natural crystals and its Sr-dominant synthetic analogue demonstrated that curite is slightly non-stoichiometric, with the general structural formula $\mathrm{Pb}_{3+x}\left(\mathrm{H}_{2} \mathrm{O}\right)_{2}\left[\left(\mathrm{UO}_{2}\right)_{4} \mathrm{O}_{4+x}(\mathrm{OH})_{3-x}\right]_{2}$, where $x=0.08$ for case of natural crystals. ${ }^{29,30}$ Those studies suggested a charge-balance mechanism in the structure, however, they were not able to resolve positions of the $\mathrm{H}$ atoms within the structure. The structure of curite is based upon the uranyl-oxo-hydroxide sheets of the curite topology (Fig. 1a with ${ }^{[9]} \mathrm{Pb}_{3+x}{ }^{2+}\left(\mathrm{H}_{2}{ }^{[5]} \mathrm{O}\right)_{2}$ complex between the sheets (Fig. 1c). These sheets consist of infinite chains of equatorial edge-sharing pentagonal bipyramids and highly distorted square bipyramids (in an unusual ratio of $3: 1$ ); that are corner-linked with intermittent triangular motifs (Fig. 1b). The diffraction studies along with electronmicroprobe analysis revealed that the $\mathrm{Pb}$ content in curite is somewhat variable and balanced by a charge compensating change of the $(\mathrm{OH})$ content within the sheets.

\section{X-ray diffraction}

Long-prismatic fragment $(0.074 \times 0.028 \times 0.008 \mathrm{~mm})$ of curite crystal from the locality Shinkolobwe, the Shaba province, Democratic Republic of Congo was used for single-crystal X-ray

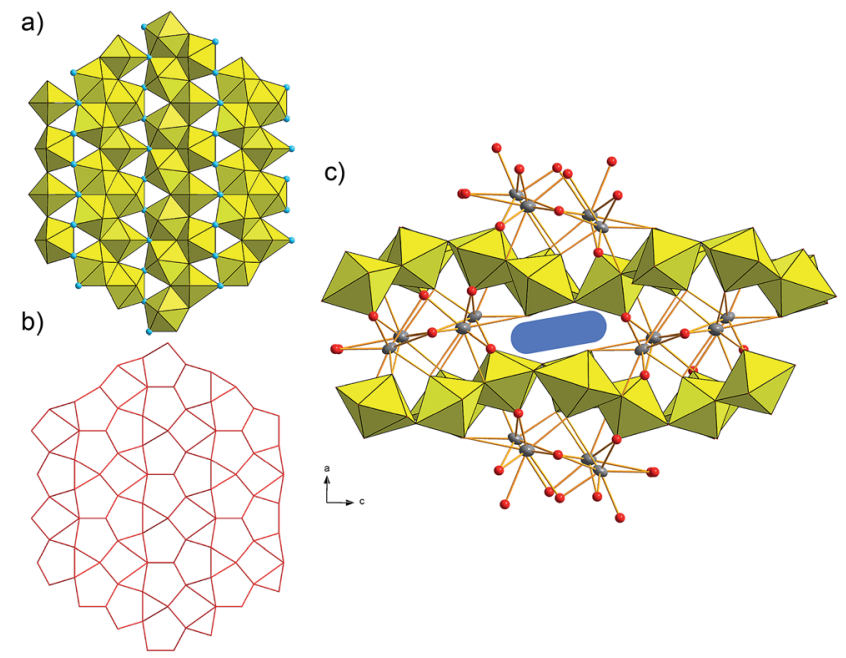

Fig. 1 (a) Uranyl-oxy-hydroxide ( $U \mathrm{OH})$ sheet present in the structure of curite, and (b) its corresponding sheet uranyl-anion topology. (c) Crystal structure of curite view down [010] with corrugated UOH sheet and $\mathrm{Pb}$ atoms (grey) in interlayer. Voids in the structure (marked in blue) are populated by $\mathrm{H}$ atom of the $\mathrm{OH}$ groups. $\mathrm{H}$ atoms omitted for better clarity.

diffraction experiment. The X-ray data collection was done at room temperature with a Rigaku SuperNova single-crystal diffractometer $\left(\mathrm{MoK}_{\alpha}\right.$ radiation from a micro-focus X-ray tube collimated and monochromatized by mirror-optics and detected by an Atlas S2 CCD detector). In line with previous structure determinations it has been found that curite is orthorhombic, space group Pnma, with $a=12.5510(10), b=8.3760(4), c=$ 13.0107(9) $\AA, V=1367.78(16) \AA^{3}$, and $Z=2$. Integration of the diffraction data, including corrections for background, polarization and Lorentz effects and absorption correction was carried out with the CrysAlis RED program. Crystallographic data and experimental details are given in Table 1. The structure of curite was solved by the charge-flipping algorithm using the SHELXT program. ${ }^{31}$ The structure was then refined using the software Jana2006 with the full-matrix least-squares refinement based on $F^{2}{ }^{32}$ Structure solution revealed position of all atoms except of hydrogens. The position of hydrogen atoms were ascertained from the difference Fourier maps. The $\mathrm{H}$ atoms were refined using a mix of soft constraints on $\mathrm{O}-\mathrm{H}$ distances, 0.98(4) $\AA$, and with the $U_{\text {eq }}$ of each $\mathrm{H}$ set to 1.2 times that of the donor $\mathrm{O}$ atom. Details on the $\mathrm{H}$ atoms refinement from the $\mathrm{X}$ ray data are below. Final atom coordinates and displacement parameters as obtained from the refinement and selected interatomic distances can be found as ESI. $\dagger$ Results of the bondvalence analysis ${ }^{33}$ are given in Table 2; the bond-valence parameters were taken from recent review by Gagné \& Hawthorne. ${ }^{34}$ The summary of the $\mathrm{H}$-bonds geometry is given in Table 3, along with the fractional coordinates obtained both from X-rays and calculations.

\section{Torque method calculations}

The orientation of $\mathrm{H}_{2} \mathrm{O}$ molecule was optimized with the Torque method, a robust and fast real-space method for determining 
Table 1 Miscellaneous crystallographic data for curite

\begin{tabular}{llll}
\hline$a(\AA)$ & $12.551(1)$ & Radiation & MoK $\alpha$ \\
$b$ & $8.3760(4)$ & Reflections & 15611 \\
$c$ & $13.0107(9)$ & Independent reflections & 1732 \\
$V\left(\AA^{3}\right)$ & $1367.78(16)$ & Independent reflections with $I>3 \sigma(I)$ & 1374 \\
$Z$ & 2 & & \\
Space-group & $P n m a$ & $R$ & \\
$D_{\text {calc. }}\left(\mathrm{g} \mathrm{cm}^{-3}\right)$ & 7.404 & (obs.) \\
Crystal size $(\mathrm{mm})$ & $0.074 \times 0.028 \times 0.008$ & wR (obs.) \\
$\mu\left(\mathrm{mm}^{-1}\right)$ & 65.78 & GOF & 3.53 \\
& & & 7.16 \\
\end{tabular}

$\mathrm{H}_{2} \mathrm{O}$ orientations from rotational equilibrium. ${ }^{27}$ The same study showed that Torque predicted equilibrium orientations and experiment lead to the same hydrogen bond topology. In the Torque method, the $\mathrm{H}_{2} \mathrm{O}$ molecules are placed such that its oxygen matches the location known from experiment. In contrast the locations of the two hydrogens are not required. They are chosen according to the water model that provides the charges of the oxygen and hydrogen in the water molecules, here TIP3P. ${ }^{35}$ The initial orientation of the $\mathrm{H}_{2} \mathrm{O}$ molecule(s) is (are) randomly chosen. The charges of the remaining ions, $\mathrm{Pb}$, $\mathrm{U}, \mathrm{O}$, and $\mathrm{H}$ were taken from two models: the first model is based on common oxidation states; the second model utilizes Brown bond-valence charges ${ }^{33}$ as obtained for the refined curite structure (Table 2). The partial occupancies of the two $\mathrm{Pb}$ sites (Table S1 $\dagger$ ) have been taken into account, by modeling fully occupied sites but multiplying the $\mathrm{Pb}$ charges with the siteoccupancy. Therefore, the charges remain consistent with the chosen charge model, and the site contribution to electrostatics is rescaled by the site-occupancy, as explained in ref. 27. With these definitions we have a complete electrostatic model that allows deriving forces and computing torques. The torques are used to guide the water orientation toward rotational equilibrium. We tested each charge model for 500 randomly chosen initial orientations, in total 1000 configurations. The results of the Torque method reported below refer to the statistical analysis of the Torque predicted rotational equilibrium orientations.
Table 3 Hydrogen-bond geometry (in $\AA$ and ${ }^{\circ}$ ) in the structure of curite and corresponding coordinates for the $\mathrm{H}$ atoms from the two sets obtained from the Torque method refinement

\begin{tabular}{lllll}
\hline $\mathrm{D}-\mathrm{H} \cdots \mathrm{A}$ & $\mathrm{D}-\mathrm{H}$ & $\mathrm{H} \cdots \mathrm{A}$ & $\mathrm{D} \cdots \mathrm{A}$ & $\mathrm{D}-\mathrm{H} \cdots \mathrm{A}\left(^{\circ}\right)$ \\
\hline $\mathrm{O} 5-\mathrm{H} 5 \cdots \mathrm{O} 2$ & $0.98(3)$ & $2.08(12)$ & $2.915(15)$ & $141(13)$ \\
$\mathrm{O} 12-\mathrm{H} 12 \cdots \mathrm{O} 11$ & $0.97(4)$ & $1.91(5)$ & $2.831(18)$ & $158(11)$ \\
$\mathrm{O} 4-\mathrm{H} 4 \mathrm{a} \cdots \mathrm{O} 1$ & 1.00 & 2.00 & 2.97 & 164 \\
$\mathrm{O} 4-\mathrm{H} 4 \mathrm{~b} \cdots \mathrm{O} 9$ & 0.95 & 1.92 & 2.87 & 170 \\
\hline
\end{tabular}

\section{Results}

\section{Structure revealed from X-ray data}

General crystal architecture is in line with previous structure determinations. ${ }^{29,36}$ The current structure refinement (Table 1) provided nearly the same results regarding the occupancy of the two interlayer $\mathrm{Pb}$ sites. There are two $\mathrm{OH}$ sites within the structural unit, associated with $\mathrm{O} 5$ and $\mathrm{O} 12$ atom, and one $\mathrm{H}_{2} \mathrm{O}$ site $(\mathrm{O} 4)$ in the structure according to the bond-valence analysis (Table 2). The site-scattering refinement and the bond-valence considerations resulted in the structural formula ${ }^{[9]} \mathrm{Pb}_{3.02}{ }^{2+}\left(\mathrm{H}_{2}{ }^{[5]} \mathrm{O}\right)_{2}\left[\left(\mathrm{UO}_{2}\right)_{4} \mathrm{O}_{4.02}(\mathrm{OH})_{2.98}\right]_{2}, Z=2$.

\section{Determination of $\mathrm{H}$ atoms from X-ray data}

Localization of the $\mathrm{H}$ atoms in the structure of curite based on $\mathrm{X}$-ray data appeared to be relatively straightforward in case of $\mathrm{H}$ atoms associated with the $(\mathrm{OH})$ groups within the structural

Table 2 Bond-valence analysis for curite (values in valence units, vu; $\times 2 \downarrow, \times 2 \rightarrow$ : multiplicity; $\sum B V$ : sum of bond-valences)

\begin{tabular}{|c|c|c|c|c|c|c|c|c|c|c|}
\hline & $\mathrm{U} 1$ & $\mathrm{U} 2$ & U3 & $\mathrm{Pb} 1$ & $\mathrm{~Pb} 2$ & H5 & $\mathrm{H} 12$ & $\mathrm{H} 4 \mathrm{a}$ & $\mathrm{H} 4 \mathrm{~b}$ & $\sum B V$ \\
\hline O1 & 1.55 & & & $0.21 \times 2 \downarrow$ & $0.24 \times 2 \downarrow$ & & & 0.08 & & 2.07 \\
\hline $\mathrm{O} 2$ & & & 1.51 & 0.18 & & & & & & 1.76 \\
\hline $\mathrm{O} 4$ & & & & & $0.25 \times 2 \downarrow$ & & & 0.83 & 0.92 & 2.08 \\
\hline O5 & 0.59 & $0.54 \times 2 \downarrow$ & & & & 0.86 & & & & 2.00 \\
\hline O6 & $0.71 \times 2 \rightarrow$ & 0.67 & & & 0.11 & & & & & 2.19 \\
\hline O9 & & & 1.57 & 0.07 & 0.25 & & & & 0.10 & 1.98 \\
\hline O10 & $0.59 \times 2 \rightarrow$ & & 0.58 & 0.26 & & & & & & 2.03 \\
\hline O11 & & 1.59 & & & 0.06 & & 0.10 & & & 1.75 \\
\hline $\mathrm{O} 12$ & 0.36 & & 0.59 & & & & 0.89 & & & 1.84 \\
\hline$\sum B V$ & 5.92 & 6.02 & 6.04 & 1.87 & 1.85 & 0.93 & 0.99 & 0.91 & 1.01 & \\
\hline
\end{tabular}


units. There are two difference Fourier maxima, first localized $0.99 \AA$ (charge $0.43 e$ ) from 012 (OH group), and second localized $1.08 \AA$ (charge $0.32 e$ ) from O5 (OH group). These two can be successfully refined providing a reasonable bonding-geometry (Table 3).

Additionally, there is a difference Fourier electron density associated with atom $\mathrm{O} 4$, which according to the bond-valence analysis (Table 2) belong to a $\mathrm{H}_{2} \mathrm{O}$ group. Nevertheless, the best attempts to assign $\mathrm{H}$ positions resulted in unreasonably large $\mathrm{H}-\mathrm{O}-\mathrm{H}$ angles. The refinement with a single $\mathrm{H}$ atom associated to the $\mathrm{O} 4$ site, which lies at the inversion-center, returned two symmetrically related $\mathrm{H} 4$ and $\mathrm{H}_{4}^{\prime}$ atoms, that both belong to the Pnma (8d) site, with an implied $\mathrm{H} 4-\mathrm{O}-\mathrm{H} 4^{\prime}$ angle of $180^{\circ}$, assuming full occupancy of the (8d) site. To conclude, structure refinement from powder data provided a reasonable position for hydrogen in the $\mathrm{O}-\mathrm{H}$ groups while the positions of water and the induced hydrogen bonding network remained unresolved. The Torque method does not rely on the hydrogen locations of water and was initialized from the final X-ray refinement results, exclusive the (8d) site hydrogen atoms of $\mathrm{H}_{2} \mathrm{O}$, and proceeded as described in the previous section on Torque method calculations.

\section{Torque predicted $\mathrm{H}_{2} \mathrm{O}$ orientations in curite}

The oxidation state of $\mathrm{Pb}$ is consistent with inferences from ionic radii. $\mathrm{Pb}^{2+}-\mathrm{O}$ is expected to be $\sim 2.6 \AA$ and $\mathrm{Pb}^{4+}-\mathrm{O}$ is expected to be $\sim 2.2 \AA$. Comparing these values with ESI (Table $\mathrm{S} 3 \dagger$ ) for the experimental bond length supports that $\mathrm{Pb}$ is in a $2+$ oxidation state, a finding that is also consistent with BV results (Table 2). The first charge model for the Torque method consists of common oxidation states, $+2,+6,-2$, and +1 , for $\mathrm{Pb}$, $\mathrm{U}, \mathrm{O}$, and $\mathrm{H}$, respectively. The second charge model uses the BV charges as derived for the refined structure (Table 2). The unit cell for model 1 is charge neutral while for model 2 it carries a small net charge of approximately $-0.25 e$ per unit cell. The detailed analysis of the rotational equilibrium orientations obtained from 500 random initial orientations for each of the two charge models (1000 initial orientations in total) shows that they converge to five distinct final orientations, irrespective of the charge model. The distribution of the converged orientations over these 5 configurations is dominated by one configuration (Fig. 2), that occurs with a frequency of $\geq 80 \%$ and hydrogen in sites H4a and H4b (Fig. 2 and Table 3). H4a and $\mathrm{H} 4 \mathrm{~b}$ represent two distinct rotational equilibrium orientations about the same oxygen. The detailed analysis of these two configurations shows that they are related to each other through inversion symmetry. For both water orientations one $\mathrm{O}-\mathrm{H}$ bond is sub-parallel to the (linear) $\mathrm{H} 4-\mathrm{O}-\mathrm{H} 4^{\prime}$ direction, as identified in our X-ray refinements. In addition, the Torque method allowed identifying the orientation of the remaining $\mathrm{O}-\mathrm{H}$ bonds and to clarify the nature of the hydrogen bonding network. Thus, the Torque method results strongly suggest that the hydrogen (8d) site is only half occupied, in agreement with our $\mathrm{X}$-ray structure refinement. The same two orientations dominate in both charge models, showing that the Torque method is

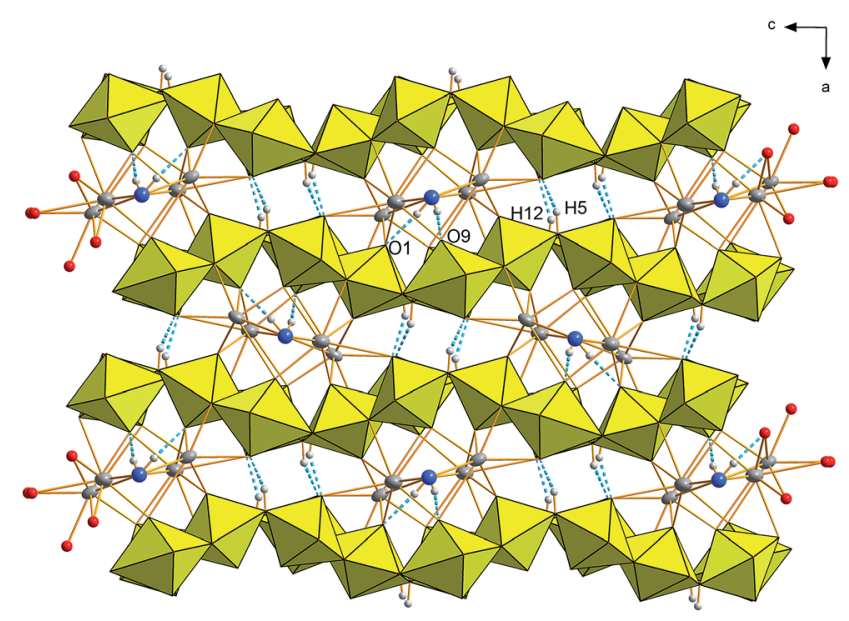

Fig. 2 Hydrogen-bonds network in the structure of curite as proposed from $\mathrm{X}$-ray data and the Torque method. The $\mathrm{O} 4$ atom of the $\mathrm{H}_{2} \mathrm{O}$ group is blue, $\mathrm{H} \cdots$ acceptor bonds are displayed in light blue color

robust even in cases where the net charge of the unit cell is not exactly zero and corroborating our experimental findings.

\section{Discussion}

Results from both X-ray experiments and the Torque method revealed hydrogen bonds network in the mineral curite. While the orientation of the $\mathrm{OH}$ groups is more or less reliable from the X-ray data, the meaningful orientation of the $\mathrm{H}_{2} \mathrm{O}$ molecule in the structure was only possible with the help of Torque calculations. The H-bond network is schematically given in Fig. 2. The H-bond associated with the $\mathrm{O} 5(\mathrm{OH})$ atom is accepted by the $\mathrm{O} 2$ atom. The $\mathrm{H}$-bond emanating from $\mathrm{O} 12$ $(\mathrm{OH})$ atom is accepted by $\mathrm{O} 11$ atom. Both bonds provide bondvalence contributions that stabilize the otherwise undersaturated $\mathrm{O}$ atoms, in terms of its bond-valence requirements (Table 2). Two hydrogen bonds emanating from the $\mathrm{H}_{2} \mathrm{O}$ molecule $(\mathrm{O} 4)$ are as follows $\mathrm{O} 4-\mathrm{H} 4 \mathrm{a} \cdots \mathrm{O} 1$ and $\mathrm{O} 4-\mathrm{H} 4 \mathrm{~b} \cdots \mathrm{O}$ 9. All $\mathrm{H} \cdots \mathrm{A}$ bondlengths are reasonable, resulting in a bond-strength of $\sim 0.10$ vu.

Nevertheless, the charge-balance mechanism that takes place in the curite structure, in order to balance the nonstoichiometry of the $\mathrm{Pb}$ content, has remained unclear. Yet previous structure determinations excluded a $\mathrm{H}_{2} \mathrm{O} \rightarrow(\mathrm{OH})$ substitution in the interlayer; a mechanism that is supported and favored by the results of our study. Most likely the balance is kept by the local $(\mathrm{OH}) \leftrightarrow \mathrm{O}_{2}$ substitution; however, resolution of such process is far beyond the possibilities of the refinement from X-ray data.

One of the classifications of molecular $\mathrm{H}_{2} \mathrm{O}$ in the structures of inorganic solids is following their role in the structure bonding. ${ }^{21,22,37}$ Particular types of $\mathrm{H}_{2} \mathrm{O}$ can be distinguished based on the coordination number of $\mathrm{O}$ atoms in these $\mathrm{H}_{2} \mathrm{O}$ groups: there are transformer, non-transformer, and inverse transformer $\mathrm{H}_{2} \mathrm{O}$ groups with [3], [4], and [5]-fold coordinated $\mathrm{O}$ atoms, respectively. Their role is generally to transfer the bond- 
valence from cations (Lewis acids) to anions (Lewis bases), keeping the structure together, as the strengths of these components are equal or similarly matching, following the valence-matching principle of the bond-valence theory. ${ }^{20,37}$ In the structure of curite, there is a single $\mathrm{H}_{2} \mathrm{O}$ group, where the coordination number of the donor $\mathrm{O}$ atom is [4]; therefore it is expected to involve a non-transformer $\mathrm{H}_{2} \mathrm{O}$ group. This finding is in disagreement with the composition predicted by a theoretical approach, which is based on bond-valence calculations, used previously. ${ }^{22}$ According to that, curite should contain at least one inverse-transformer group. Nevertheless, the current finding that, most probably there is not any inverse-transformer $\mathrm{H}_{2} \mathrm{O}$ group similar to the case of lead-uranyl-silicate mineral kasolite, which was also predicted to contain inversetransformer $\mathrm{H}_{2} \mathrm{O}$ group. ${ }^{22,38}$ Thus, the combination of experiment and theory, provides access to the previously lacking crystallography of the hydrogen bonding network in curite. Therefore, our study provides an important pre-requisite for understanding the mechanisms that stabilize the structure of this hydrated uranium oxysalt mineral.

\section{Conclusions}

Previous experimental studies on the crystal structure of leaduranyl-oxide mineral curite, ideally $\mathrm{Pb}_{3}\left(\mathrm{H}_{2} \mathrm{O}\right)_{2}\left[\left(\mathrm{UO}_{2}\right)_{4}\right.$ $\left.\mathrm{O}_{4}(\mathrm{OH})_{3}\right]_{2}$, lacked the positions of hydrogen atoms as it was not possible to localize them from single-crystal X-ray diffraction data due to high absorption of the mineral phase $\left(\mu \sim 66 \mathrm{~mm}^{-1}\right.$ for the Mo-radiation). In the present study, the complete crystal structure of curite has been determined by using a combination of X-ray diffraction data and rotational equilibrium simulations (Torque method). This method was shown previously to be a robust and simple approach for determining the orientation of $\mathrm{H}_{2} \mathrm{O}$ molecules in complex inorganic structures. Current results show that curite is slightly non-stoichiometric in $\mathrm{Pb}$ contents and a charge balance mechanism via $(\mathrm{OH}) \leftrightarrow \mathrm{O}_{2}$ substitution within the structural sheets. Unlike earlier prediction, the current study shows that curite contains only one non-transformer $\mathrm{H}_{2} \mathrm{O}$ group. The hydrogen bonding system maintains the bonding between the sheets additionally to $\mathrm{Pb}-\mathrm{O}$ bonds; among them a H-bond between the $\mathrm{OH}$ group and an apical $\mathrm{O}_{\text {Uranyl }}$ atom in the adjacent sheet (Fig. 2) is crucial for thermodynamic stability. Thus, the combination of experiment and the rotational equilibrium condition provides new insights into $\mathrm{H}_{2} \mathrm{O}$ bond networks in complex structured oxides that are needed to advance our understanding of SNF materials and their interaction with the environment.

\section{Conflicts of interest}

There are no conflicts to declare.

\section{Acknowledgements}

We thank Simon Philippo (Musée National d'Histoire Naturelle, Luxembourg) for providing us curite specimen for the study. JP thanks to the support of the project no. LO1603 under the
Ministry of Education, Youth and Sports National Sustainability Program I of the Czech Republic. BK and SG would like to thank the National Science Foundation for computing resources acquired through the infrastructure grant NSF-EAR-IF-1661985.

\section{Notes and references}

1 S. V. Krivovichev and J. Plášil, in Uranium: from Cradle to Grave, ed. P. C. Burns and G. E. Sigmon, MAC Shourt Course, 2013, vol. 43, pp. 15-119.

2 J. Plášil, J. Geosci., 2014, 59, 99.

3 R. J. Finch and R. C. Ewing, J. Nucl. Mater., 1992, 190, 133.

4 R. J. Finch and T. Murakami, Rev. Mineral. Geochem., 1999, 38, 91-180.

5 J. Plášil, Eur. J. Mineral., 2018, 30, 237.

6 J. Janeczek, R. C. Ewing, V. M. Oversby and L. O. Werme, J. Nucl. Mater., 1996, 238, 121.

7 R. C. Ewing, Nat. Mater., 2015, 14, 252.

8 K. Maher, J. R. Bargar and G. E. Brown Jr., Inorg. Chem., 2013, 52, 3510 .

9 Y. Zhang, J. Čejka, G. R. Lumpkin, T. T. Tran, I. Aharonovich, I. Karatchevtseva, J. R. Price, N. Scales and K. Lu, New J. Chem., 2016, 40, 5357.

10 Y. Zhang, R. Aughterson, I. Karatchevtseva, L. Kong, T. T. Tran, J. Čejka, I. Aharonovich and G. R. Lumpkin, New J. Chem., 2018, 42, 12386.

11 M. L. Miller, R. J. Finch, P. C. Burns and R. C. Ewing, J. Mater. Res., 1996, 11, 3048.

12 P. C. Burns, Can. Mineral., 2005, 43, 1839.

13 S. V. Krivovichev, Crystal Chemistry of Uranium Oxides and Minerals, in Comprehensive Inorganic Chemistry II, Elsevier, 2013, pp. 611-640.

14 F. Colmenero, J. Cobos and V. Timón, Inorg. Chem., 2018, 57, 4470.

15 J. Plášil, J. Geosci., 2018, 63, 65.

16 M. T. Weller, M. E. Light and T. Gelbrich, Acta Crystallogr., Sect. B: Struct. Sci., 2000, 56, 577.

17 J. Brugger, N. Meisser, B. Etschmann, S. Ansermet and A. Pring, Am. Mineral., 2000, 296, 229.

18 K. Walenta and T. Theye, Neues Jahrbuch Mineral. Abhand., 2012, 189, 117.

19 F. C. Hawthorne, Z. Kristallogr., 1992, 201, 183.

20 F. C. Hawthorne, Phys. Chem. Miner., 2012, 39, 841.

21 F. C. Hawthorne and M. Schindler, Z. Kristallogr., 2008, 223, 41.

22 M. Schindler and F. C. Hawthorne, Can. Mineral., 2008, 46, 467.

23 M. Schindler and F. C. Hawthorne, Can. Mineral., 2004, 42, 1601.

24 F. Colmenero, A. M. Fernández, J. Cobos and V. Timón, J. Phys. Chem. C, 2018, 122, 5254.

25 F. Colmenero, A. M. Fernández, J. Cobos and V. Timón, J. Phys. Chem. C, 2018, 122, 5268.

26 F. Colmenero, A. M. Fernandez, V. Timón and J. Cobos, RSC Adv., 2018, 8, 24599.

27 S. Ghazisaeed, J. Majzlan, J. Plášil and B. Kiefer, J. Appl. Crystallogr., 2018, 51, 1116. 
28 A. Schoep, C. R. Acad. Sci., 1921, 173, 1186.

29 Y. Li and P. C. Burns, Can. Mineral., 2000, 38, 727.

30 P. C. Burns and Y. Lil, Can. Mineral., 2001, 38, 175.

31 G. M. Sheldrick, Acta Crystallogr., Sect. A: Found. Adv., 2015, 71, 3.

32 V. Petříček, M. Dušek and L. Palatinus, Z. Kristallogr., 2014, 229, 345.

33 I. D. Brown, The Chemical Bond in Inorganic Chemistry: The Bond Valence Model, Oxford University Press, 2002, pp. 1278.
34 O. C. Gagné and F. C. Hawthorne, Acta Crystallogr., Sect. B: Struct. Sci., Cryst. Eng. Mater., 2015, 71, 562.

35 W. L. Jorgensen, J. Chandrasekhar, J. D. Madura, R. W. Impey and M. L. Klein, J. Chem. Phys., 1983, 79, 926.

36 K. Mereiter, TMPM, Tschermaks Mineral. Petrogr. Mitt., 1979, 26, 279.

37 F. C. Hawthorne, Am. Mineral., 2015, 100, 696.

38 K. Fejfarová, M. Dušek, J. Plášil, J. Čejka, J. Sejkora and R. Škoda, J. Nucl. Mater., 2013, 434, 461. 